\title{
A escrita do testemunho em Memórias do Cárcere*
}

\author{
ALFREDOBOSI
}

Vivíamos num ambiente de fantasmagorias

(Mémorias do cárcere, II, cap. 20)

$\mathrm{E}$

STE ENCONTRO remete, desde o título, a Graciliano memorialista. A nossa atenção é chamada a examinar os laços que prendem o autor do depoimento à história política brasileira dos anos 30. Acontece, porém, que o depoente é um dos três ou quatro maiores prosadores da nossa literatura, de modo que seria perder-nos em descaminhos querer interpretar as suas lembranças de preso desconsiderando os padróes narrativos e estilísticos que as enformaram.

A proposta deste breve estudo é trançar alguns fios que a leitura da obra vai mostrando como significativos. A questão de base que se deve enfrentar é esta: como a memória de fatos históricos se fez construção literária pessoal sem descartar o seu compromisso com o que vulgarmente se entende por realidade objetiva?

Uma palavra ajuda a avançar na solução do problema acima formulado. Essa palavra é testemunho.

Recentemente os jurados de um concurso latino-americano, patrocinado pela Casa de las Américas de Havana, adotaram a expressão literatura de testemunho para qualificar um tipo de escrita que desde os anos Setenta não cessa de crescer. A escolha do termo obedeceu à necessidade de acolher um alto número de originais que se situavam na intersecção de memórias e engajamento. Nem pura ficção, nem pura historiografia; testemunho.

A expressão é bifronte, e daí vem a sua riqueza.

O testemunho quer-se idôneo, quer-se verídico, pois aspira a certo grau de objetividade. Como tal, casa memória individual com história.

* Este e os dois textos seguintes foram apresentados na mesa-redonda Graciliano Ramos: memória e historia, realizada no anfiteatro do Departamento de História da FFLCH-USP, em 22 de outubro de 1992. A sessão, organizada pelo Instituto de Estudos Avançados e pelo Instituto de Estudos Brasileiros, da USP, contou com a participação dos professores Alfredo Bosi, Boris Schnaiderman, Jacob Gorender e Jorge Coli, e a coordenação do professor Zenir Campos Reis. 
Mas o testemunho também se sabe obra de uma testemunba, que é sempre um foco singular de visão e elocução. Logo, o testemunho é subjetivo e, por esse lado, se aparenta com a narrativa literária em primeira pessoa.

O testemunho vive e elabora-se em uma zona de fronteira. As suas tarefas são delicadas: ora fazer a mímese de coisas e atos apresentando-os "tais como realmente aconteceram" (conforme a frase exigente de Ranke), e construindo, para tanto, um ponto de vista confiável ao suposto leitor médio; ora exprimir determinados estados de alma ou juízos de valor que se associam, na mente do autor, às situaçóes evocadas.

As Memórias do cárcere dão o paradigma dessa complexidade textual. Ao percorrê-las, somos levados tanto a reconstituir a fisionomia e os gestos de alguns companheiros de prisão de Graciliano, quanto a contemplar a metamorfose dessa matéria em uma prosa una e única - a palavra do narrador.

Começo reparando em um dado intrigante: a ausência quase completa de discussão ideológica sustentada ao longo das memórias. Nada há nestas que lembre, por exemplo, os cadernos de cárcere contemporâneos de Antonio Gramsci, saturados de polêmicas e de juízos sobre as ideologias do tempo no seu país e no mundo. Seria fácil alegar, para o caso, a desproporção de nível cultural que estremava os dois escritores e que distinguia as respectivas esquerdas. A diferença pesa, mas não parece ser a razão maior daquela escassez de humus ideológico observável no texto de Graciliano. Eu diria que o autor simplesmente não se propôs olhar e, menos ainda, avaliar os seus companheiros enquanto sujeitos de um drama político.

A lacuna poderá servir de pista. A testemunha é, neste caso, antes um observador arredio e perplexo do que um intérprete empenhado em dar uma explicação articulada dos valores cuja defesa levou aqueles militantes à desgraça. É uma visada tópica, que se detém no horizonte mais próximo possível da situação vivida e não se dispõe a ultrapassá-lo como se receasse dizer mais do que sabe.

O narrador contempla corpos sofridos que às vezes emitem palavras, talvez idéias, farrapos de idéias, mas estas importam-lhe pouco em si mesmas. A solidariedade que lhe inspiram aqueles homens é existencial, para não dizer estritamente corporal. Não é a luta partidária de cada um que o afeta, mas o seu modo próprio de estar naquelas condiçóes adversas, o seu jeito de sobreviver.

Daí nasceria o desaponto, quando não a irritada frustração de alguns leitores sectários da obra que nela esperavam encontrar um libelo ortodoxo, mas topavam com uma voz desconfiada, avessa à condenação por princípio e ao louvor distribuído por tabela. Era a expressão de uma razão modesta que o tolhimento 
da cela tornara ainda mais ciente dos próprios limites. A escrita do testemunho tem a ver com essa voz-em-situação.

Alguma coisa sempre se sabe das crenças e descrenças do narrador. Que ele é refratário ao capitalismo. Que não tem religião nenhuma. Que sente uma antipatia visceral pelo estado prepotente, pela polícia brutal, pelo submundo da política nordestina, pela estupidez burocrática. Mas nada disso o leva a fazer corpo comum com os militantes presos, muitos deles envolvidos na intentona de $\mathbf{3 5}$ ou dissidentes do Partido Comunista que já então se digladiavam em polêmicas ferozes. Os atores daquele golpe desastrado pareciam-lhe improvisadores canhestros; e a nossa pequena burguesia de esquerda, incapaz de seguir coerentemente uma liderança revolucionária. Tudo era precário, sem base na vida popular de um Brasil pobre e disperso.

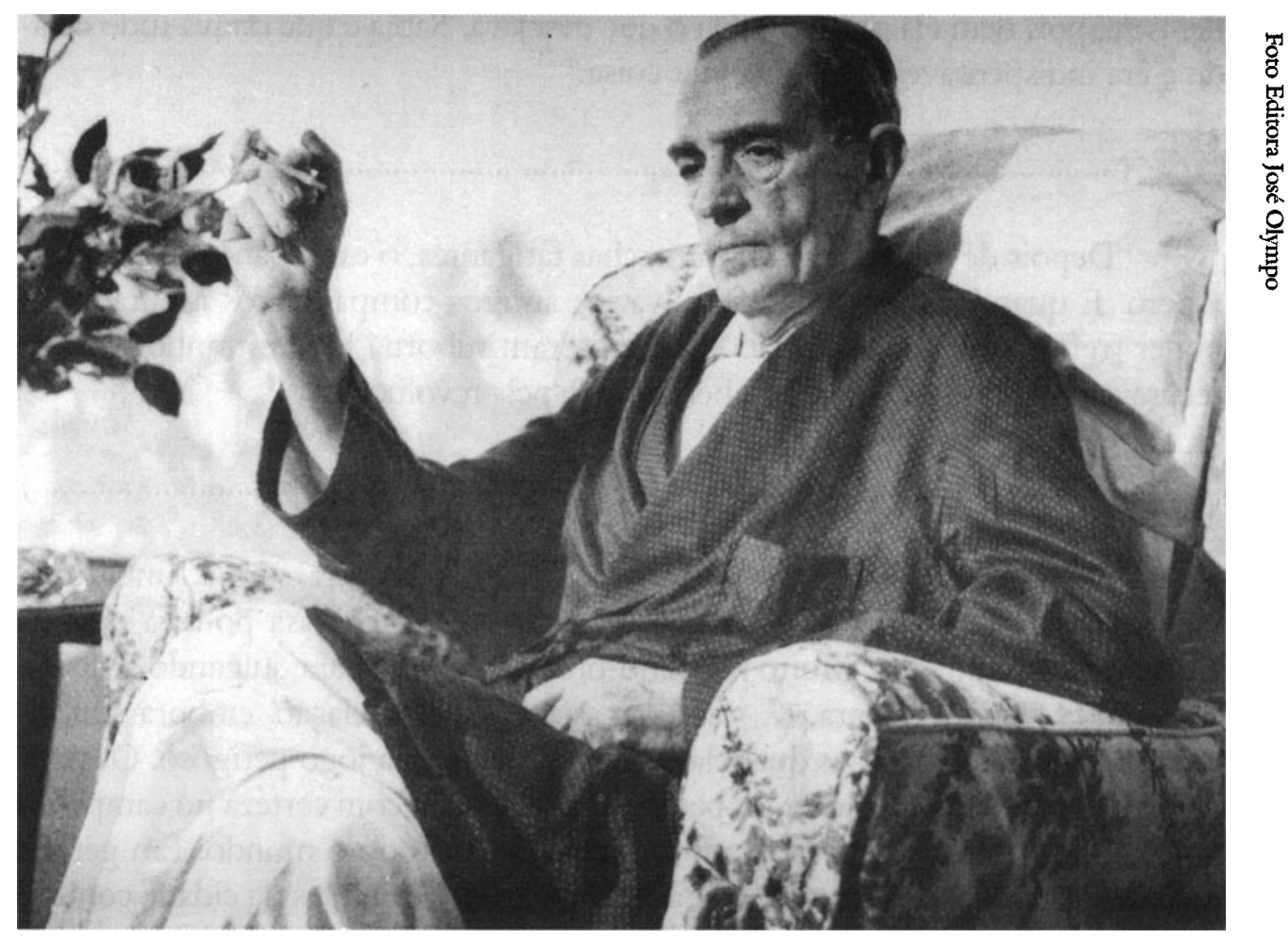

Graciliano Ramos (1892-1953), antor de Memórias do Cárcere

Nenhuma dessas marcas negativas, porém, é trabalhada a fundo, quer em termos teóricos (o crítico não pensa em armar esquemas políticos alternativos), quer em termos práticos: o observador não tem propostas de curto prazo. A certa altura, supõe que será rotulado de "revolucionário chinfrim", sem garra para resistir às injustiças que sabe apontar com tanta agudeza... 
Em meio a tanta negação há um capítulo, $09^{\circ}$ da primeira parte, que se lê com alívio. São três páginas simpáticas à pessoa de Luís Carlos Prestes, embora céticas em relação à Coluna e incertas quanto a seus desdobramentos políticos:

"Eu não tinha opinião firme a respeito desse homem. Acompanhara-o de longe em 1924, informara-me da viagem romântica pelo interior, daquele grande sonho, aparentemente frustrado. Um sonho, decerto: nenhum excesso de otimismo nos faria ver na marcha heróica finalidade imediata. Era como se percebêssemos na sombra um deslizar de fantasma ou sonâmbulo. Mas essa estranha figura de apóstolo disponível tinha os olhos muito abertos, examinava cuidadosamente a vida miserável das nossas populações rurais, ignorada pelos estadistas capengas que nos dominavam. Defendia-se com vigor, atacava de rijo; um magote de vagabundos em farrapos alvoroçava o exército, obrigado a recorrer aos batalhóes patrióticos de Floro Bartolomeu, ao civismo de Lampião. Que significava aquilo? Um protesto, nada mais. Se por milagre a coluna alcançasse a vitória, seria um desastre, pois nem ela própria sabia o que desejava. Sabia é que estava tudo errado e era indispensável fazer qualquer coisa."

(

"Depois de marchas e contramarchas fatigantes, o exilio, anos de trabalho áspero. $\mathrm{E}$ quando, num golpe feliz, vários antigos companheiros assaltaram o poder [refere-se à Revolução de 30] e quiseram suborná-lo, o estranho homem recusava o poleiro, declarara-se abertamente pela revolução."

"De repente voltava; a Aliança Nacional Libertadora surgia, tinha uma vida efêmera em comícios, vacilava e apagava-se. Estaria essa política direita? Assaltavam-me dúvidas. Muito pequeno-burguês se inflamara, julgando a vitória assegurada, depois recuara. (...) Seria possível uma associação, embora contingente e passageira, entre as duas classes? Isso me parecia jogo perigoso. Os interesses da propriedade, grande ou pequena, a lançariam com certeza no campo do fascismo, quando esta miséria ganhava terreno em todo o mundo. Em geral a revolução era olhada com medo ou indiferença. Os habitantes da cidade contentavam-se com discursos idiotas, promessas irrealizáveis e artigos safados, animavam-se à-toa e depressa desanimavam (...); as populaçôes da roça distanciavam-se enormemente do litoral e animalizavam-se na obediência ao Coronel e a seu Vigário, as duas autoridades incontrastáveis."

(

"Ainda não dispunha de meios para avaliar com segurança a inteligência de Prestes: dois ou três manifestos, repreensões amargas aos antigos companheiros, 
eram insuficientes. Admirava-lhe, porém, a firmeza, a coragem, a dignidade. $\mathrm{E}$ sentia que essa grande força estivesse paralisada.

- Com os diabos!" (I, 79-82).

Páginas adiante, Graciliano declara-se alheio ao Partido Comunista (na época da sua prisão) e ao "barulho de 1935".

Chama a atenção o modo pelo qual o líder comunista mais conhecido em todo esse período é qualificado, por duas vezes, de estranbo: "essa estranha figura de apóstolo", "o estranho homem". Ou então, pela variante: "essa criatura singular". Ou ainda: "fantasma", "sonâmbulo". E diz "romântica" a sua viagem pelos sertóes do país, "um grande sonho aparentemente frustrado".

É como se o olhar da testemunha mal conseguisse divisar os contornos de uma figura que viveria na condiçáo mista de pessoa empírica e personagem de ficção. Homem, sim, e dos mais rijos e prestantes, mas também fantasma. Soldado alerta, atento às mazelas do país e, no entanto, sonâmbulo. Revolucionário temido e ao mesmo tempo apóstolo. Em suma, uma criatura singular.

Singular: 0 adjetivo assenta bem em uma obra narrativa, na qual é o indivíduo que importa, a sua face única e ímpar, ao passo que o discurso histórico tende a compor um grande número de fisionomias para melhor construir a alegoria de um grupo, de um movimento social ou de toda uma geração. Mas a nossa testemunha fala aqui de uma só pessoa, e não de um tipo.

Como entender esse ponto de vista? Uma respeitável tradição crítica viu no estilo de Graciliano Ramos uma depuração extrema do realismo do século XIX. Teríamos o nossos clássico desse realismo (1). Não há quem ignore o seu trabalho árduo de linguagem sempre à procura do termo justo, da frase seca e sóbria, da perfeita concisão. Um realismo vigiado, portanto, sem generalizações levianas de foco onisciente, distinto do naturalismo de Eça e de Alú́sio, com os quais guardaria, porém, algum raro ponto de contato. E expressão de modernidade, também, embora de costas para os vanguardismos de 22 . Essa, a situação do autor. De todo modo, a verdade de um grande texto começa quando as classificações acabam: convém repensar o que seria o realismo de Graciliano quando a sua escrita é testemunhal.

A definição mais feliz que conheço a respeito é a de Otto Maria Carpeaux: o realismo em Graciliano se fazproblemático. O crítico o opõe ao realismo de José Lins do Rego, que seria organico.

Ambas as palavras já dizem muito por si mesmas, mas creio que vale a pena 
aprofundar o significado da primeira notação quando aplicada ao texto das $M e$ mórias. Por que realismo problemático?

As situações vividas na cadeia, o narrador as concebe como enleadas, difíceis de penetrar. $O$ caráter aleatório da perseguição política que the foi movida por desafetos em Alagoas (talvez integralistas, é o que sugere no começo do livro), o aspecto enigmático da sua condição de preso sem formação de processo e a atmosfera kafkiana dessa mesma experiência, tudo se reflete difusamente na sua escrita. Há sempre alguma coisa de indistinto, de mal aclarado e mal resolvido nos episódios lembrados. O embaraço diante dos fatos estende-se à compreensão dos companheiros. Quase todos the parecem opacos. Mal se inicia uma tentativa de comunicação já nascem os equívocos. $\mathrm{O}$ esforço mental de sondar as intenções do outro rende tão pouco que logo sobrevém uma sensação de fadiga, uma tentação de desistência, o que leva mais de uma vez ao estado de reconcentrado encaramujamento.

O peso da negatividade e o empatamento cognitivo parecem obstar a que o narrador arme um laço de simpatia com o próximo. Este ou é recusado por um movimento crispado de desconfiança, ou mantém o seu estatuto de problema, se não de enigma. Do lado do sujeito, o processo conduz a uma exaustão que não é compensada, em momento algum, pela conquista da paz interior:

"A fadiga me entorpecia a carne, mas o fervedouro de pensamentos desconexos não me deixava repousar" (II, 12). "Descerrando as pálpebras pesadas, inteirava-me de minúcias que não se articulavam". "O conjunto era uma aglomeração de tipos reconhecíveis um instante e logo a esfumar-se em neblina; envoltório de redes e capotes davam-lhe uma feição vaga de fardos instáveis".

Essa aglomeração e essas minúcias desconexas são o objeto construído por um realismo diferenciado, atuante na escrita pensativa de um homem que procura apreender a forma e o sentido das coisas, mas em vão. O mundo é "fumacento e fuliginoso", "as minúcias embaralhavam-se, perdiam-se", era "difícil desenovelar tais incongruências".

A perspectiva dominante é a que vai da interrogação à estranheza e, nos casos extremos, fecha-se na recusa. Não é um realismo solar, é um realismo plúmbeo.

Se do ângulo do conhecimento a visada do narrador é problemática (enquanto insiste na presença dos óbices que se interpóem entre o eu e os outros), no que toca à expressão afetiva há uma tonalidade difusa de mal-estar. Os sentimentos recorrentes são de tédio à comunicaçãa, aborrecimento, embaraço, enfezamento, 
apoquentação, quizília, azucrinamento e, para tudo resumir, infernização. É o léxico familiar de Graciliano.

Esse matiz entre cinza e negro que se espalha pelas páginas do memorialista já se advertia no modo pelo qual Paulo Honório em São Bernardo e Luís da Silva em Anguistia encaravam as demais personagens e a si mesmos. Viviam ambos um clima de suspeita e culpabilidade. Em ambos o motivo último da escrita tem a ver com o remorso. Um sentimento turvo que nada parece apaziguar, pois não é nem a contrição do arrependido nem o mergulho nas águas tépidas da autocomiseração. O que punge o narrador é a consciência de uma infelicidade que, embora comum a todos, não consegue ser partilhada. Uma consciência infeliz que separa, que irrita e estorva a comunicação.

Dialeticamente, o remorso, que é efeito de uma quebra (culposa ou não, sempre angustiante) no processo de comunicação, acaba movendo o sujeito a empreender o seu único projeto de relação continuada com o outro: a palavra escrita, que converte o próximo em leitor distante, e o interlocutor presente e molesto em sombra ignota e muda. Talvez cúmplice.

No caso do escritor destas memórias a aproximação imediata se dá com o $e u$ de Infáncia. Quem leu este livro extraordinário decerto lembrará o quanto os afetos atribuídos ao menino também entram nesse contexto de ilhamento sem perdão, a começar pela sua conversa frustrada com a mãe. E em Vidas secas o capítulo "O menino mais velho" é a metaforização do diálogo infeliz do menino com Sinha Vitória a partir da pergunta que ele lhe faz: "o que é inferno?" É a passagem toda que responde: inferno é não poder perguntar, nem mesmo à mãe, o que é inferno sem cair no risco de sofrer um ato de violência. A infelicidade, que fez calar a criança e recalcou a sua palavra, se mudaria na consciência de uma espinhenta solidão no adulto cuja escrita remoerá a percepção difícil, a relação truncada. O processo valerá, talvez, para a obra inteira de Graciliano.

Nem sempre a negatividade se sustém em alto nível de tensão, de alerta cognitivo. Nem sempre o foco da escrita se contém e guarda em silêncio palavras e juízos. Às vezes a linguagem do narrador decai a gesto brusco de rejeição e roça a violência. Então o léxico naturalista trai o primeiro Graciliano, o leitor de Eça, o Eça do típico e do caricato. Assim, Eusébio, o velho polaco reacionário, "grunhia" palavras, e o narrador descreve a sua "interjeição asmática" e as suas "lamentaçóes pegajosas". Em vez de nariz e lábios, aparecem focinho e beiços. Mas são registros esparsos, momentos de desabafo. Predomina a notação contida, a mediação do pensamento cujos tateios dizem o receio de lançar estigmas, julgamentos peremptórios. $\mathrm{O}$ enleio diante das próprias percepçōes impede $\mathbf{o}$ escritor de recorrer ao traço grosso do velho naturalismo feito de sarcasmo e degradação. A testemunha mantém a sua perspectiva habitual de perplexidade. 
Reagindo a uma oferta generosa, mas incompreensível, de empréstimo da parte de um oficial, comenta o narrador:

"Horrivel mal-estar, o desejo inútil de arrancar do interior qualquer coisa (...). Freqüentemente me surgiam na alma sulcos negros, hiatos, e as idéias se embaralhavam, a fala esmorecia, trôpega; havia agora, porém, espessa névoa e, através dela, muito longe, uma figura confusa a apertar-me rijo a mão, a desaparecer no alpendre, com certeza julgando-me estúpido e ingrato" (I, 107).

E este rasgo de auto-análise intelectual:

"O espírito estava lúcido, mas era lucidez esquisita: percebia tipos, ocorrências, em fragmentos; quando se tratava de estabelecer relaçäo, surgiam cortes, hiatos, falhas alarmantes" (I, 165).

O realismo, quando sobe a este ponto crítico, sabe que toda memória é precária ou, no melhor dos casos, apenas seletiva. Se o narrador fixa detalhes isolados de uma figura humana, não o faz, em geral, para convertê-los em metonímias caricatas (os naturalistas, ao contrário, se compraziam nos efeitos de ridículo ou grotesco que produz a nomeaçáo das partes corporais). Nas Memórias o recorte do pormenor supõe a confissão honesta de que a totalização seria um ideal muito difícil de alcançar e talvez incompatível com os limites da testemunha:

"Escrevi até à noite. Se houvesse guardado aquelas páginas, com certeza acharia nelas incongruências, erros, hiatos, repetições. $O$ meu desejo era retratar os circunstantes, mas, além dos nomes, escassamente haverei gravado fragmentos deles: os olhos azuis de José Macedo, a contração facial de Lauro Lago, a queimadura horrivel de Gastão, as duas cicatrizes de Epifânio Guilhermino, o peito cabeludo e o rosário do beato José Inácio, a calva de Mário Paiva, os braços magros de Carlos Van der Linden, o rosto negro de Maria Joana iluminado por um sorriso muito branco" $(I, 22)$.

\section{A crise do preconceito}

Além de admitir a incerteza dos seus juízos de realidade, o memorialista sente que deve rever alguns de seus juízos de valor mais arraigados. A vida na prisão traz à luz o lado vil dos que, fora dela, se supóem indefectivelmente briosos. Em contrapartida, desperta naqueles que a ordem social já votou ao desprezo centelhas de inesperada dignidade e humana compaixão: 
"Precisamos viver no inferno, mergulhar nos subterrâneos sociais, para avaliar ações que não poderíamos entender aqui em cima” ( $I, 150)$.

A testemunha é desafiada a reelaborar as suas opinióes convencionais e o narrador hesita com receio de cair vítima de preconceitos endurecidos. E afinal, o que será o preconceito se não a generalização abusiva de alguma experiência, real sim, mas singular e descontínua em relação a outras de que a aproxima o nosso arbítrio? ,

Um primeiro exemplo. O nosso preso entreviu, sonolento, um vulto de policial negro encostado à amurada do navio. Imediatamente veio-lhe à mente a imagem de outro soldado, também negro, que no dia anterior o obrigara a descer a escada fixando-lhe uma pistola às costelas. No entanto as duas figuras, olhadas com atenção, eram bem diversas entre si, e só a imaginação temerosa poderia têlas superposto. " $\mathrm{O}$ indivíduo ali próximo não se assemelhava ao bruto corpulento: era um rapaz alto, magro, de feiç̧óes humanas; debruçado, parecia examinar o interior do porão". Desfeito o equívoco, Graciliano pede ao policial negro um copo d'água, e este lhe satisfaz o pedido, não uma so, mas quatro ou cinco vezes, apesar da dificuldade que o favor lhe custa em razão da distância e do desnível que separava a rede e a amurada. $O$ narrador comenta:

"Estranho, estranho demais. A fadiga alquebrava-me, impedia-me esboçar um sorriso de reconhecimento. (...) Ato gratuito, nenhuma esperança de paga; qualquer frase conveniente, resposta de gente educada, morreria isenta de significaçáo. Na véspera, outro desconhecido, negro também, me havia encostado um cano de arma à espinha e à ilharga; e qualquer gesto de revolta ou defesa passaria despercebido. Esquisito. Os acontecimentos me apareciam desprovidos de razão, as coisas não se relacionavam. A violência fôra determinada apenas pela grosseria existente no primeiro negro; o ato caridoso pela bondade que havia no coração do segundo. Ausência de motivo fora isso, eu não merecia nenhum dos dois tratamentos. (...) Nunca percebera, em longos anos, casos semelhantes" (I, 150).

Violência ou solidariedade podem irromper de modo aleatório, a qualquer momento, no anonimato do cárcere. O que oprime o sujeito, aqui tornado objeto, é não saber de quem virão, nem quando, nem como, nem por que. Graciliano narraria uma situação análoga em Vidas secas no episódio da cadeia.

A testemunha, golpeada pelo acaso que a desnorteia, pensa de imediato nas razốes do coração. Uns o teriam bom, outros não. Mas, como é bivalente o seu ponto de vista, ora só depoente, ora também intérprete, tenta às vezes seguir o caminho mais árduo da integração histórica. $\mathrm{E}$ aí o estudioso de ciências humanas se surpreenderá ao encontrar nesse observador de condutas solitárias um perspicaz analista das razóes culturais que as enformam. 
Penso no episódio do advogado Nunes Leite que atravessa o pátio do quartel tomado por um choro convulsivo, "Um soluço, único soluço, uivo rouco; não subia nem descia; enquanto durou a passagem ressoou monótono, invariável: parecia que o homem não tomava fôlego". Uma expressão tão incontida de desespero (o coitado nem sequer levava as mãos ao rosto para esconder o pranto) causou estranheza ao narrador. E, no começo, desprezo. Mas depois veio a reflexão. Por que teria chorado de maneira tão despudorada o doutor Nunes Leite? Covardia? Alguma fraqueza do corpo ou da mente? A testemunha procura ir além dessas causas individuais e julga descobrir a razão maior das lágrimas no choque sofrido pelo profissional da Lei ao saber que os seus clientes, todos presos políticos, já não poderiam mais apelar para o direito de habeas corpus. No regime de exceção que se instalava - sob o olhar complacente de não poucos magistrados - as garantias legais sofriam medidas de restrição ou suspensão. Num átimo o Dr. Nunes viu esboroar-se o edifício onde habitara longa e confiadamente. De repente quebrara-se o ritmo lento das demandas e das prorrogaçóes. Onde agora a segurança do fórum, a solenidade dos tribunais, o recurso às precatórias, aos ofícios encaminhados aos meritíssimos juízes, devidamente selados e devidamente assinados com firmas reconhecidas? "Uma prepotência desabusada surgira - e aluiam muralhas de papel'. Se as formas cristalizadas havia séculos já não mais valiam, então era porque se destruía a substância mesma da vida social! Era o caos que estava chegando! Só restava mesmo chorar, e chorar sem esperança nem vergonha. "Era por isso talvez que o bacharel Nunes Leite chorava" (I, 100).

Temos aqui um cruzamento raro, moderno, de análise psicológica e interpretação cultural. Esse efeito de densidade se produz quando a escrita da memória avança e transpõe a fronteira que a separa da reflexão sobre valores coletivos que imantam os gestos do indivíduio.

Aliás, sempre que o narrador sonda o processo interno de um comportamento, o preconceito perde o solo aparentemente sólido onde se fincava. É a hora da dúvida. O espírito indaga em vez de rejeitar ou condenar. Essa mudança na ótica da testemunha ocorre mais de uma vez. Em relação aos militares de baixo escalão, por exemplo, de quem o preso só esperava ouvir palavras brutais, mas em quem surpreende gestos de nobreza e respeito ao próximo. No caso, visto acima, do bacharel que desatou em pranto, o observador passou do olhar desdenhoso a uma larga compreensão existencial.

Em outra passagem, é a coriácea moral sertaneja que exprime, em um primeiro momento, o seu nojo pelos homossexuais da cadeia. Mas depois, meditando na história de vida daqueles infelizes, vítimas quase sempre de chantagens de velhos presos viciados, corrige o tom do seu julgamento e considera necessário passá-lo pelo filtro de uma visão menos categórica e mais refletida do outro. 
Atitude que começa suspeitando das razóes do intelecto classificador para, em seguida, alcançar modos de pensar mais humanos:

"As minhas conclusões eram na verdade incompletas e movediças. Faltavame examinar aqueles homens, buscar transpor as barreiras que me separavam deles, vencer este nojo exagerado, sondar-lhes o íntimo, achar lá dentro coisa superior às combinações frias da inteligência".

E esta descida inesperada ao subsolo do homem dito normal, civilizado:

"Penso assim, tento compreendê-los - e não consigo reprimir o nojo que me inspiram, forte demais. Isto me deixa apreensivo. Será um nojo natural ou imposto? Quem sabe se ele não foi criado artificialmente, com o fim de preservar o homem social, obrigá-lo a fugir de si mesmo?” (I, 306).

A testemunha faz, com toda a sua despretensão, as vezes de um crítico radical do senso comum que se alimenta de estereótipos.

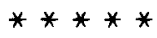

\section{Escrita e consciência}

Pode-se ir além da constataçáo e perguntar:

- Até que ponto o autor-testemunha se mostra consciente de que o filtro subjetivo é tão relevante para a construção do seu texto quanto as situaçóes objetivas que ele se propôs representar?

No capítulo de abertura das Memórias Graciliano nos dá algumas pistas para responder a essa questão.

Ressalta, em primeiro lugar, a sua firme convicção de que o testemunho não é documento histórico no sentido tradicional de espelho fiel da realidade:

"Realmente há entre os meus companheiros sujeitos de mérito capazes de fazer sobre os sucessos a que vou referir-me obras valiosas. Mas são especialistas, eruditos, inteligências confinadas à escrupulosa análise do pormenor, olhos afeitos a investigaçóes em profundidade. (...) Não me agarram métodos, nada me força a exames vagarosos. Por outro lado, não me obrigo a reduzir um panorama, sujeitá-lo a dimensóes regulares, atender ao paginador e ao horário do passageiro de bonde".

Em outras palavras: eu não sou nem historiador nem jornalista profissional. 
Em segundo lugar, como decorrência das afirmaçôes anteriores: a escrita do testemunbo deve dispor de uma considerápel margem de liberdade:

"Posso andar para a direita e para a esquerda como um vagabundo, deter-me em longas paradas, saltar passagens desprovidas de interesse, passear, correr, voltar a lugares conhecidos. Omitirei acontecimentos essenciais ou mencioná-los-ei de relance, como se enxergasse pelos vidros pequenos de um binóculo; ampliarei insignificâncias, repeti-las-ei até cansar, se isto me parecer conveniente".

Teríamos esboçada nestas passagens uma teoria da prosa memorialista, segundo a qual há uma larga distância entre o observador supostamente neutro e o escritor que contrai ou expande a seu critério a matéria recordada. $O$ autor não propóe absolutamente que a testemunha dê um salto para o discurso da imaginação; mas legitima um modo livre, nada ortodoxo, de tratar o fluxo da memória.

O realista subordina-se aqui, manifestamente, ao perspectivismo.

Em terceiro lugar, Graciliano elabora uma justificação do seu à-vontade narrativo em termos da constituição do que ele chama perdade superior. Uma verdade que se atingiria pelo exercício da intuição pessoal, que é sempre uma entre as leituras possíveis dos homens e dos fatos.

Lembro a passagem em que o narrador aceita de bom grado a perda dos seus apontamentos tomados no dia-a-dia da prisão. Os papéis tinham sido atirados na água em uma hora de dificuldade. Mas sem eles Graciliano sente-se aliviado, isto é, dispensado de anotạr certas precisóes compulsivas: "mortificar-meia por dizer com rigor a hora exata de uma partida".

O que importava ao memorialista, passados dez anos dos acontecimentos, era construir uma versão que não pretendesse erigir-se em interpretação consensual e universal (meta da História cientificista); mas que fosse tão-só aquela versão aderente às suas lembranças insubstituíveis do vivido.

Nessa linha, o autor arrisca uma proposição temerária que visa a abalar o mito da fidedignidade dos relatos baseados em pesquisas miúdas. Falando de certos dados circunstanciais que acompanharam a hora de uma despedida, afirma: "Essas coisas verdadeiras podem não ser verossímeis" (I, 36).

Se levarmos a sério o pensamento que ditou o aparente paradoxo da asserção, diremos que Graciliano estaria aqui, sem qualquer propósito deliberado, tangenciando a célebre distinção feita por Aristóteles entre o trabalho do historiador e o verbo do poeta, creditando a este último um alcance mais universal, "mais filosófico", se comparado ao primeiro. E voltamos à expressão "uma verda- 
de superior". A testemunha, que não é, nem quer ser, historiador de profissão, produz um depoimento que é sempre válido, mesmo que remeta a um sentido oculto à maioria dos circunstantes da situação evocada.

O historiador convencional sente-se obrigado a preferir o voto da maioria e a preterir a voz isolada, pois julga, na esteira dos velhos juristas romanos, que a fala da testemunha singular nada prova: unus testis, nullus testis... No entanto, precisamente porque pode ter escapado a muitos a intuição do depoente solitário, o leitor deve atentar para o que este tem a dizer. A sua voz faz parte de um coro não raro contraditório e desarmônico. Um ouvido fino captará acordes que não chegam a afetar ouvidos moucos ou distraídos. Do mesmo modo, o olhar perspicaz, coisa sempre rara, vê o que passa despercebido à maioria desatenta. Nesse caso, a verdade subjetiva de uma só testemunha poderá valer pela verdade objetiva que a História pretende guardar e transmitir. Nas palavras do autor: "A existência anormal obrigava-me a considerar verdadeiro o relato singular, a princípio com relutância, depois a dizer comigo mesmo que as coisas não se poderiam passar de maneira diferente" ( $I, 330)$.

A força da palavra de Graciliano nestas memórias vem da sua coragem de relativizar tanto as versōes alheias quanto as próprias. É um exercício de dúvida que não chega a paralisar a enunciação, mas a torna modesta. A pergunta é freqüentemente o seu bordão metódico:

"Onde estará o erro? Nesta reconstituição de fatos velhos, neste esmiuçamento, exponho o que notei, o que julgo ter notado. Outros devem possuir lembranças diversas. Não as contesto, mas espero que não recusem as minhas: conjugam-se, completam-se e não [nos?] dão hoje impressão de realidade" $(\mathrm{I}, 36)$.

Chega o momento-limite em que o narrador tem de enfrentar o buraco negro de toda reexumaçáo do passado: a queda no vazio do esquecimento. Quando falha até mesmo o concurso das lembranças de outras testemunhas, a saída razoável é admitir que os fatos olvidados por todos carecem provavelmente de valor. Só fica o que significa para alguém:

(As coisas) "que esmorecem, deixá-las no esquecimento: valiam pouco, pelo menos imagino que valiam pouco. Outras, porém, conservaram-se, cresceram, associaram-se, e é inevitável mencioná-las".

O problema crucial não estaria nem nas coisas esquecidas por todos, nem nas que são por todos lembradas. Mas naquelas de que só a testemunha tem memória. Embora não recebam confirmação da memória alheia, integram uma verdade superior, "uma verdade expressa de relance nas fisionomias", que o narrador percebeu e atesta mesmo sob pena de contradizer a versáo majoritária e corrente. 


\section{Dos limites do sujeito}

Pontuando firmemente as suas distâncias em relação ao discurso histórico, nem por isso a escrita do testemunho aceita confundir-se com a prosa de ficção.

Definitivamente, o nosso memorialista não se propóe inventar o que quer que seja por amor a efeitos estéticos. Contenta-se com a sua parcela de verdade: não deseja alterá-la comprazendo-se em jogos imaginários. Até mesmo o uso, aliás inevitável, do promome $e u$, esse "pronomezinho irritante", parece-lhe indiscreto, sinal de intromissão abusiva do sujeito:

"Desgosta-me usar a primeira pessoa. Se se tratasse de ficção, bem: fala um sujeito mais ou menos imaginário" (I, 37).

Igualmente repugna-lhe a idéia de inventar pseudônimos para esconder a identidade dos companheiros, e "fazer do livro uma espécie de romance". E nos romances, como declara em outro passo, contam-se mentiras" (II, 281).

Trata-se de um depoente, um homem que não pretende abandonar o seu compromisso de base com a fidelidade à própria consciência, admitindo sempre que é falível a sua percepção, lacunosa a memória e tateante o seu juízo ético.

Memórias do cárcere: nesta obra realista e clássica a modernidade se afirma pelo reconhecimento da força e dos limites do sujeito.

\section{Nota}

1 Cito apenas alguns marcos iniciais da fortuna crítica de Graciliano: Otto Maria Carpeaux, Origens e fins, Casa do Estudante do Brasil, 1943; Álvaro Lins, Jornal de Critica, $6^{\mathrm{a}}$ série, José Olympio, 1951; Antonio Candido, Ficção e confissão, José Olympio, 1956; Rolando Morel Pinto, Graciliano Ramos, autor e ator, Faculdade de Filosofia de Assis, 1962; Antonio Candido, Tese e antitese, Cia. Ed. Nacional, 1964; Rui Mouräo, Estruturas, Ed. Tendência, 1969.

Alfredo Bosi é professor de Literatura Brasileira na Faculdade de Filosofia, Letras e Ciências Humanas da USP e editor da revista Estudos Avançados. É autor de $A$ dialética da Colonizałáa (Companhia das Letras, 1992), entre outros livros. 